\title{
Valoraciones de la justicia y las acciones afirmativas. Reflexiones a partir de la firma de los acuerdos de paz de Colombia en 2016*
}

\author{
Mary Luz Alzate Zuluaga** \\ Universidad Nacional de Colombia
}

\section{Resumen}

En este artículo se discuten los cambios de los marcos valorativos en las nociones disponibles de justicia, preguntando ¿Cómo se va ensanchando el horizonte de lo justo en la sociedad? Este interrogante se aborda metodológicamente a partir del caso de Colombia y la firma de los Acuerdos de Paz en la Habana (Cuba) en 2016, en dos escenarios de indagación, el primero, las teorías contractuales y críticas que aportan aspectos relevantes para una definición de la justicia de manera universal, abstracta y general, pero aplicable y deseable, en sentido concreto, específico y contextual. El segundo escenario, las acciones afirmativas que van configurando actos significativos en la vida de una sociedad, para defender, transformar o rechazar valores hegemónicos y, por ende, ampliar los horizontes de justicia a través del reconocimiento de derechos y las expresiones de sensibilidad y solidaridad moral frente a la privación estructural material y el daño o sufrimiento individual.

Palabras clave: Colombia (Thesaurus); marcos de justicia, acciones afirmativas, vanguardias intelectuales, Acuerdos de paz (Autor).

\footnotetext{
*Artículo recibido: 13 de junio de 2018 / Aceptado: 15 de agosto de 2018 / Modificado: 20 de agosto de 2018. Las reflexiones desarrolladas en el presente artículo surgieron y se profundizaron en el marco de una investigación actualmente en ejecución y dos cursos ofrecidos por la autora. Un curso acerca de las acciones afirmativas y el segundo curso sobre la construcción de marcos de justicia en el contexto del pos acuerdo en Colombia, ambos ofrecidos en la Universidad Nacional de Colombia, sede Medellín, a lo largo de cuatro semestres (2014-2017). No contó con financiación.

** Doctora en Ciencias Políticas y Sociología por la Universidad Complutense de Madrid (Madrid, España). Profesora asociada en dedicación exclusiva del Departamento de Ciencias Políticas, Universidad Nacional de Colombia (Medellín, Colombia). Últimas publicaciones: Acciones colectivas frente a situaciones de violencia en el México del último lustro. Un análisis desde la decisión y el reconocimiento de sujetos políticos. Análisis Político, 30(89), 127-151, 2017 y Las agendas en plural: formal, percibida y real (en coautoría con G. Romo Morales). Guadalajara: Universidad de Guadalajara, 2015. Correo electrónico: mlalzatez@unal.edu.co iD https://orcid.org/0000-0001-7173-3357
} 


\title{
Assessment of Justice and Affirmative Actions. Reflections on the Signing of the Peace Agreements of Colombia in 2016
}

\begin{abstract}
In this article we discuss the changes undergone by evaluative frameworks regarding the available notions of justice by asking how the horizon of fairness is broadening in society. Methodologically, this question is addressed by analyzing the case of Colombia and the signing of the Peace Agreements in Havana (Cuba) in 2016. We examine two scenarios of inquiry: in the first place, the contractual and critical theories that provide relevant aspects for a definition of justice in a universal, abstract and general way, but that are also applicable and desirable in a concrete, specific and contextual sense. In the second place, we examine the affirmative actions that configure significant acts in the life of a society to defend, transform or reject hegemonic values and, therefore, expand the horizons of justice through the recognition of rights and expressions of sensitivity and moral solidarity in the face of material structural deprivation and individual suffering.
\end{abstract}

Keywords: Colombia (Thesaurus); frameworks of justice, affirmative actions, intellectual vanguards, peace agreements (Author).

\section{Introducción}

Abordar la discusión de la justicia en medio de la diversidad de valoraciones y concepciones de la misma. Con esto se busca propiciar el debate acerca de qué justicia adoptar en una sociedad como la colombiana, donde han emergido en las últimas décadas numerosos colectivos sociales en defensa de su diversidad sexual, étnica, territorial frente al extractivismo, de género, entre otras demandas sociales. Con logros importantes para quienes los conforman a través de sentencias constitucionales, el reconocimiento de sus derechos y, con ello, de los primeros pasos para su garantía, consultas populares de iniciativa ciudadana y, en general, progresos sociales hacia una opinión pública más incluyente frente a las diferencias, entre otros avances.

También se ha dado el proceso de transición hacia la dejación de armas de un grupo importante que había estado en armas por más de cincuenta años -la guerrilla de las Fuerzas Armadas Revolucionarias de Colombia-Ejército del Pueblo (FARC-EP)-, y la desmovilización de otros actores del conflicto armado previamente -grupos paramilitares-. En contraste, han emergido grupos armados denominados Bandas Criminales - o Bacrim, los Grupos Armados Organizados (GAO), los Grupos Armados Organizados Residuales (GAO residual)-, o Grupos 
Delictivos Organizados (GDO) ${ }^{1}$, cada uno de estos actores dejando, a su vez, una estela de dolor y nuevas víctimas que requieren atención y tratamiento frente a su sufrimiento.

En este panorama surge la pregunta acerca de qué justicia defender. Para intentar dar respuesta a esta pregunta se propone en el primer apartado, presentar de forma discrecional y sintética las nociones de autores que han debatido profundamente sobre las concepciones de la justicia y los rasgos más relevantes para su aplicabilidad. En el segundo apartado, se toma la noción de justicia defendida en las prácticas de las acciones afirmativas, donde se destaca que son los actores sociales movilizados frente a las injusticias percibidas colectivamente, los que propician la existencia pública de nuevas nociones de lo justo y, a su vez, se examina el peso prescriptivo y axiológico de las acciones afirmativas que se han producido en Colombia para el cambio valorativo y, por ende, para el ensanchamiento de los horizontes de lo justo en el tratamiento de los problemas públicos, al buscar un trato igualitario de quienes se han visto histórica y sistemáticamente excluídos y discriminados, por un lado. Y al comenzar a implementarse la Justicia Especial para la Paz (JEP), dando vía así a un tipo de justicia transicional derivado de los acuerdos de paz firmados entre el gobierno colombiano y la guerilla de las FARC-EP, por el otro.

\section{Las concepciones de justicia: aportes de teorías del contractualismo contemporáneo y teorías críticas sociales}

Las vanguardias intelectuales, filósofos políticos y pensadores sociales han construido alrededor de la justicia debates para la identificación de procesos perennes frente al cambio, con la incorporación e institucionalización de ideas, teorías, significados y puntos de vista morales. Por ello, se aborda la relevancia que le dan a la justicia algunos autores con respecto al significado de los conceptos en la ordenación ética, teórica y práctica de una sociedad:

Cada concepto, con sus principios asociados, define un punto de vista desde el cual pueden valorarse las instituciones, las acciones y los proyectos de vida. Un sentido de justicia es un deseo efectivo de aplicar y de actuar según los principios de la justicia y, por tanto, desde el punto de vista de la justicia. Así, lo que hay que establecer es qué es racional (tal como se define en la teoría específica del bien) para los que se encuentran en una sociedad bien ordenada como afirmación de su sentido de justicia como regulador de su proyecto de vida. (Rawls, 1995 [1971], p. 512)

1. Entre muchos otros informes uno que sintetiza el tema, véase: Matta (2018). 
Es con este planteamiento acerca del papel ordenador, vinculante y creador de horizontes sociales y políticos de ideas y conceptos clave como lo es la justicia, que se presentarán aportes complementarios, ideas, caminos axiológicos y prácticos de comprensión de las relaciones sociales y políticas contemporáneas, para lo cual se identifican aspectos relevantes de las teorías de Jhon Rawls, Martha Nussbaum, Nancy Fraser, Axel Honneth y Seyla Benhabib. Rawls, es uno de los autores más influyentes en la construcción teórica de una concepción contemporánea de la justicia, en la medida que concibe la justicia de manera transversal y amplía a la existencia de una estructura básica social, en la que tendrían que considerarse de manera ideal unos principios, como condiciones formales mínimas para una distribución "imparcial" de derechos y deberes entre cada uno de los integrantes de esa estructura social.

Tal distribución tendría que derivar en un trato igualitario que beneficiara a todas las personas, Rawls contempla la posibilidad de una distribución desigual, natural o artificial, pero en mayor beneficio de aquellos con alguna dificultad o desventaja. En sus palabras,

todos los bienes sociales primarios -libertad, igualdad de oportunidades, renta, riqueza, y las bases de respeto mutuo-, han de ser distribuidos de un modo igual, a menos que una distribución desigual de uno o de todos estos bienes redunde en beneficio de los menos aventajados. (Rawls, 1995[1971], p. 281)

De este modo, el beneficio mutuo es el mayor imperativo del acuerdo entre las partes para un trato justo. Sabiendo de antemano que este postulado de Rawls corresponde a una visión híbrida entre la mirada utilitarista y la kantiana del respeto mutuo. Esta perspectiva ha sido criticada porque este sentido de la reciprocidad sigue circunscrito a la visión utilitaria de las personas, en tanto pasa a ser más relevante la actuación de los otros siempre y cuando signifiquen un beneficio individual -en esa idea del beneficio mutuo-; es decir, es una perspectiva en la que lamentablemente queda diluído el principal rasgo del respeto mutuo, la del tratamiento de las personas como un fin y no como medios para la obtención de beneficios. Este asunto también lo discute Nussbaum, y se presentará más adelante. Por ahora, se puede servir de la defensa que hace Rancière de la necesidad de que prime la ayuda, el amor y el respeto mutuo, sobre cualquier beneficio mutuo:

La principal atención que el hombre puede esperar del hombre es esa facultad de comunicarse el placer y el dolor, la esperanza y el temor, para conmoverse recíprocamente: "Si los hombres no tuviesen la facultad, una misma facultad, de conmoverse y de enternecerse recíprocamente, se volverían pronto extraños los unos a los otros; se dispersarían aleatoriamente sobre el globo y las sociedades se disolverían [...] El ejercicio de este poder es a la vez el más dulce de todos nuestros placeres, así como la más imperiosa de nuestras necesidades". (Rancière, 2010 [2003], p. 102) 
Para sociedades en transición hacia la civilidad, por la dejación de armas y procesos de reconciliación frente a conflictos armados históricos como el vivido en Colombia, las valoraciones sobre la solidaridad, el respeto, la consideración y la integridad del otro sin que medie ningún beneficio propio, es un aspecto indispensable para el reconocimiento de las víctimas y del inicio de un tratamiento justo frente a lo que les ocurrió.

Si bien, en sus revisiones posteriores Rawls matizó las condiciones de universalidad y generalidad en los principios de justicia - de libertad y de diferencia-, planteando que eran pensados en sentido teórico e ideal para sociedades democráticas y liberales, o, más aún, "altamente industrializadas", estas primeras condiciones formales, nos permiten un panorama teorético general de justicia - nada equiparable a una concepción moral general-, basado en ciudadanos libres e iguales. La idea hipotética de una posición original es una elección metodológica, teórica e imaginaria de Rawls, bajo la cual se obraría y se razonaría dentro de un "velo de ignorancia". Sirve a la argumentación de su noción contractual de una justicia imparcial. Es decir, una situación dentro de la cual las personas en condiciones de igualdad y sin variables que pudieran afectar sus elecciones -por las preferencias debido al carácter personal, histórico, cultural, social, político, entre otros- en la estructura social.

En un sentido práctico, lo que se sugiere es que en situaciones como el posacuerdo en Colombia, donde se tuviera que estar sentados en la misma mesa, o en cualquier otra situación con excombatientes de la guerrilla, el trato y las posibilidades de decisión para las personas tendría que ser igualitario y no discriminatorio por razones de su pasado como victimario. Bajo el argumento de que con la firma de unos acuerdos entre las partes en conflicto, la construcción de una reconciliación social y la superación de los hechos; incluyendo en estos, los relatos belicistas, las posturas de odio, polarización y las relaciones amigo-enemigo, así lo requiere. Al igual que otros aspectos fundamentales para una plena superación y reconciliación social, entre estos, la reconstrucción de la memoria y verdad acerca de lo ocurrido con la reparación a las víctimas, de todas las formas posibles.

Ahora bien, Rawls en su defensa de la igualdad, negaba las ventajas naturales posibilitadas por la desigualdad de las capacidades humanas, por los esfuerzos y los meritos personales, al no considerarse en la visión de la igualdad a los distintos casos de personas con deficiencias o discapacidades físicas o mentales. Es decir, al postularse por una igualdad se puede fallar por exceso, al no reconocer a los individuos que pudieran estar por encima del umbral social o de las capacidades humanas, o por defecto, al no considerarse las deficiencias y dificultades de quienes pudieran estar por debajo de ese umbral por situaciones como la discapacidad física o mental. 
Nussbaum (2016 [2006]) profundiza esta crítica de Rawls y advierte algunos problemas para la definición de una sociedad justa: deficiencias y discapacidades; nacionalidad y pertenencia a la especie. La autora aún no presenta una solución teórica y menos aún práctica, pero parte de los avances de la teoría rawlsiana para hacer sus propios aportes. Se destaca aquí de manera sucinta lo pertinente para la noción de justicia que se propone exponer, teniendo en cuenta el pos acuerdo en Colombia. Con respecto a la primera dificultad señalada, Nussbaum plantea que en el diseño de los principios básicos a contemplar en una sociedad justa, no se incluyen personas que están por fuera de las denominaciones hegemónicas y estandarizadas de la sociedad, fundamentalmente, porque quienes están proponiendo unos mínimos acuerdos y condiciones básicas comunes de relacionamiento desde un trato justo: en igualdad y libertad, no están contemplando la diferencia de oportunidades de quienes tienen capacidades físicas y mentales con alguna desventaja frente a quienes están "legislando" o proponiendo acuerdos en una denominada "normalidad".

La segunda dificultad señalada por Nussbaum, la nacionalidad, no puede seguir eludiendo las desigualdades económicas y sociales entre países, y la inevitable vinculación e interdependiencia que hoy existe entre la desigualdad y las desventajas materiales locales o internas que se puedan vivir en determinados países frente a las relativas ventajas de los otros. ¿Cómo seguir sosteniendo el principio de igualdad bajo estas condiciones materiales reales de brecha amplia de desigualdad entre los países del llamado primer y tercer mundo? Más aún, ¿entre los mismos países de la región, caso del tratamiento de Colombia frente a los migrantes venezolanos? El argumento de Nussbaum es que el lugar de nacimiento o la nacionalidad es un factor importante en la definición de las oportunidades de las personas, y estas oportunidades van a depender de las condiciones políticas, sociales y económicas que se ofrezca al interior de los estados nacionales y de la interconexión y cooperación que se logre entre los países en apoyo a la población migrante.

Con respecto al tercer problema señalado a la teoría de la justicia imparcial, nos encontramos con la exclusión y el desconocimiento de la igual dignidad moral de otros seres vivos no humanos, como es el caso de los animales, en palabras de Nussbaum. Con respecto al trato que debería darse a los animales lo máximo a lo que nos hemos acercado en el reconocimiento es a la caridad o a la compasión y no a la justicia, señala Nussbaum.

Con respecto a la primera dificultad señalada, el rezago en las condiciones físicas y de oportunidades para el libre e igual desenvolvimiento de grupos de población con situaciones de discapacidad, migración y desplazamiento forzado interno en Colombia, obliga a la búsqueda de mecanismos que remedien sus circunstancias, y tendrá que ser observado y garantizado desde la estructura social básica, en nuestro caso el Estado, pero que ya no 
admite indiferencia por parte del resto de la población. Una de las principales objeciones de Nussbaum a la perspectiva contractualista de la justicia es la concepción imaginaria de la sociedad al beneficio mutuo. Es decir, de personas en condiciones de igualdad e independiencia buscando beneficiarse al permanecer juntas, en vez de aisladas. Esta objeción se debe, en primer lugar, a que no todas las partes interesadas tienen una posición inicial para elegir bajo condiciones de igualdad e independiencia; en segundo lugar, no todas las partes - ni siquiera idealmente- tienen el mismo anhelo o deseo de beneficiarse mutuamente; $y$, en tercer lugar, si se ubica el beneficio mutuo como una finalidad de la justicia, en vez de alcanzar la benevolencia, el amor o la misma justicia, se sigue considerado al ser humano y no humano como un medio para los otros y no como un fin en sí mismos. De estas objeciones se desprende la defensa de su enfoque de las capacidades humanas, así:

[...] la mejor forma de plantear la idea de un mínimo social básico es un enfoque basado en las capacidades humanas, es decir, en aquello que las personas son efectivamente capaces de hacer y ser, según una idea intuitiva de lo que es una vida acorde con la dignidad del ser humano [...]. También argumentaré, de nuevo confiando en la idea intuitiva de la dignidad humana, que las capacidades en cuestión deberían atribuirse a todas y cada una de las personas, para tratarlas así como fines y no como medios para los fines de otros. (Nussbaum, 2016 [2006], p. 83)

Aunque Nussbaum plantea este enfoque de las capacidades humanas con un carácter universal y pluralista, se aparta de los planteamientos relativistas - culturalmente hablandoy reconoce explícitamente que las objeciones a Rawls no se reemplazan con su propuesta de las capacidades, busca complementar esos faltantes en la mirada amplia rawlsiana de la justicia con la adopción de unos derechos sociales mínimos, y donde ninguno prime en detrimento del otro: "todos los derechos deben ser garantizados como requisitos básicos de la justicia [...] ninguno puede sustituir al otro” (Nussbaum, 2016 [2006], p. 100).

Valga aclarar que dichas capacidades son nombradas por Nussbaum, aceptando su carácter abierto e inacabado, abstracto y derivado de una concepción moral parcial, que además significa el considerar la protección de algunas libertades de manera central como la libertad de expresión, de asociación y de conciencia.

Este aspecto de la identificación de las capacidades humanas para nuestra definición de justicia, nos permite proponer a las distintas víctimas del conflicto armado en Colombia un papel de mayor protagonismo en la resolución de sus destinos. Por fuera de los rasgos pasivos, de simples receptores del daño o compasión de las consecuencias de la violencia desatada por los actores del conflicto armado. Y, al contrario, posibilitar dentro de la estructura básica social, los espacios para la expresión del dolor, la recuperación de la memoria de los hechos y el tránsito hacia la reconstrucción de sus vidas. 
Lo que implica, a su vez, por parte del resto de la sociedad colombiana el dejar de regodearnos en lo ocurrido, o de seguir increpando y señalando a los excombatientes de los distintos bandos del conflicto.

Una vez enunciado el planteamiento de las capacidades, se propone la mirada en positivo del reconocimiento que ha defendido Honneth en sus debates frente a la justicia. Dentro de las condiciones para una sociedad justa Honneth (2011) identifica en el nivel principal el reconocimiento de la dignidad e integridad individual. En su debate con Fraser acerca de la primacía o no de las luchas por el reconocimiento a partir del sufrimiento moral individual frente a las luchas por la redistribución económica y social, Honneth defiende que "las luchas por la redistribución son luchas por el reconocimiento orientadas a cambiar la interpretación cultural del éxito" (Fraser y Honneth, 2006, p. 159). En el planteamiento acerca de las reivindicaciones de redistribución material, su argumento es que el resultado proviene de dos fuentes diferentes:

Por un lado, de las implicaciones normativas de la igualdad jurídica, que garantiza un trato igualitario ante la ley de todos los miembros de una comunidad democrática [...] Pero las reivindicaciones de redistribución resultan también de la idea normativa de que cada miembro de una comunidad democrática debe tener la oportunidad de ser socialmente valorado por sus aportaciones individuales. (Honneth, 2010, p. 41)

La adopción de Honneth de una indivisibilidad de los conflictos intersubjetivos, se refiere a la idea de que el reconocimiento no es una reivindicación del individuo que se refiera meramente a unos objetivos culturales por la identidad diferenciada del individuo, sino que son conflictos por el reconocimiento integral del individuo, dentro de unas condiciones históricas, es decir, también son reivindicaciones por unos objetivos materiales y jurídicos de igualdad en la interrelación con los otros. Se trata de una lucha por el reconocimiento en todas sus dimensiones, es ésta, su concepción moral democrática basada en la teoría del reconocimiento. "Un esquema formal de la moral comprende las condiciones cualitativas de autorrealización que se puede distinguir de todas las formas de vida particulares en la medida en que constituyen premisas generales de la integridad personal de los individuos" (Honneth, 2010, p. 33).

De este modo, el aporte que permite ampliar y complementar la perspectiva de las capacidades humanas de Nussbaum es, en el planteamiento que se retoma de Honneth, el que el menosprecio a las diferencias en capacidades y facultades individuales en una sociedad conduce a la mayor dificultad para eliminar las condiciones de desigualdad que deriva en un tratamiento injusto y daño al otro. Por lo tanto, en el ensanchamiento de la idea de una sociedad colombiana actuando en justicia, es imprescindible visibilizar 
los daños a la identidad de las mujeres, de la comunidad LGBTI, de los discapacitados, y de los afrocolombianos e indígenas, para quienes han existido tipos de "reconocimiento erróneo", a los que se van a unir los grupos de migrantes - recientemente grupos de venezolanos-, o de distintas procedencias. Ahora bien, optar por alguna de las reivindicaciones no nos resuelve el problema de la justicia, y suponer que podemos elegir una opción ideal que resuelva las distintas reivindicaciones sociales y políticas, nos lleva al argumento falaz de la imparcialidad moral y política, a su vez, "no es ya el dolor físico como tal, sino la conciencia resultante de no ser reconocido en la propia concepción que uno tiene de sí mismo lo que constituye la condición del daño moral" (Honneth, 2010, p. 24).

Honneth (2011) recientemente ha discutido la idea habermasiana de la existencia de formas de moralidad empíricamente operantes, asunto relevante previo a una propuesta de qué justicia defender en el caso colombiano en la actualidad, argumentando tres asuntos sintetizados así: el primero, esa idea no hace diferencias con respecto a moralidades específicas como la de clase social, ni en sus formas ni en las condiciones para su expresión, ante lo que advierte; segundo, en determinado caso de que se expresen y de acuerdo a su forma de expresión de dichas moralidades de clase, "[...] el sentimiento de injusticia social también dependen de la eficacia del control social” (Honneth, 2011, p. 58), para concluir que, como consecuencia, podemos estar ante conflictos "práctico-morales" vividos de forma individual y aislada, lo que dificultaría, a nuestro modo de ver, la resolución colectiva. Este es un aspecto para tener en cuenta en Colombia en el emprendimiento de una reconciliación amplia, debido a que los sentimientos individuales de las víctimas frente a su dolor y pérdida tendrán que contar con canales formales e informales de expresión, además de una amplia recepción y solidaridad pública frente a la injusticia vivida.

En esa respuesta a Habermas, Honneth propone la conciencia de injusticia como concepto del cual subraya "que la moral social de las agrupaciones oprimidas no contiene representaciones independientes de la situación de un orden moral total o proyecciones de una sociedad justa, sino que presenta una sensibilidad altamente susceptible para violaciones de exigencias de moralidad supuestas de manera justificada" (Honneth, 2011, p. 60). El que exista una conciencia de injusticia requiere la identificación de distintos conflictos normativos, de clase social y de posibilidades de diferenciación individual, lo que nos lleva a la búsqueda de su articulación en discursos, teorías o en el llamado a la movilización social, propiciando la "sensibilidad moral" hacia los aspectos o condiciones de existencia de los sujetos que ven amenazada su dignidad e integridad, es decir, en todas las dimensiones del reconocimiento. La conciencia de injusticia agrega un nuevo elemento a los rasgos hasta aquí discutidos acerca de las condiciones necesarias para ampliar los horizontes de lo justo en una sociedad. 
La respuesta de Fraser frente a esas formas de moralidad empíricamente operantes, que Honneth resuelve con la conciencia de injusticia, es acerca de una mirada que supere las explicaciones teleológicas en la adopción del tipo de justicia que se impone a veces en el debate acerca de qué debería resolverse primero ¿las reivindicaciones por la igualdad socioeconómica o aquellas defendidas por la identificación como minorías excluidas y discriminadas históricamente? O más aún ¿las demandas por el acceso político y participación en el poder público en igualdad de condiciones?, tendría que aceptar la preexistencia de las distintas formas de desigualdad en un mismo ámbito social, es decir, el padecimiento de una desigualdad tripartita o múltiple por parte de las poblaciones históricamente discriminadas. Lo que nos propone un dilema:

Cuando los reclamantes sostienen puntos de vista conflictivos respecto a la sustancia de la justicia, aparece otra cuestión: ¿redistribución o reconocimiento o representación? El resultado es que se levanta la sospecha de que el ideal convencional de imparcialidad puede ser incoherente, ya que lo que se discute en la actualidad no son simplemente reivindicaciones en conflicto, sino ontologías en conflicto, que suponen criterios conflictivos en la valoración de las reivindicaciones. (Fraser, 2008, p. 19)

Nos encontramos ante varios marcos valorativos para adoptar una sola noción de justicia: el socioeconómico, el cultural y el político. Cada uno de estos marcos valorativos tiene puntos de vista rivales en la definición de los sujetos de justicia, dando respuesta a la pregunta implícita por el quienes, ya sea la de "todos los afectados"; la de víctimas en las relaciones estructurales injustas y; la respuesta que plantea al ser humano en abstracto, al hacer parte de un destino común, entre los otros posibles sujetos de justicia.

Contrastando la propuesta procedimental de la paridad participativa, con respecto a nuestro caso de análisis, la composición del Congreso colombiano a partir de las elecciones políticas del año 2018 elegido después de los Acuerdos de Paz de la Habana, no tendría porque significar para la opinión publica como una dádiva política el hecho de la existencia de curules ocupadas por los exintegrantes de una guerrilla en dejación de armas y convertida en partido político y, al contrario, sería necesario ampliar el nivel de participación a los demás actores relevantes para ese proceso de reconciliación social y política en ciernes.

Complementariamente al planteamiento de Fraser, se puede ubicar el enfoque de las capacidades de Sen (1995), para quien la evaluación de la equidad en la distribución, más que medirse en los ingresos o recursos, tendría que medir la distribución de oportunidades de acuerdo con las capacidades individuales. A. Sen plantea el enfoque de las capacidades "desde el análisis de la igualdad y de la justicia hacia las libertades 
disfrutadas, en vez de reducirse a los resultados conseguidos" (Sen, 1995, p. 96). El foco de su análisis es por las posibilidades que ofrece la estructura social para ejercer libremente su destino,

\begin{abstract}
En la valoración de la justicia basada en las capacidades, las demandas o títulos individuales no tienen que valorarse en términos de los recursos o de los bienes elementales que las personas poseen, respectivamente, sino por las libertades de que realmente disfrutan para elegir las vidas que tiene razones personales para valorar. Es esta libertad real la que esta representada por las "capacidades" de la persona para conseguir varias combinaciones alternativas de funcionamientos. (Sen, 1995, p. 97)
\end{abstract}

En el caso colombiano, el reto será cómo convertir el recurso formal de un acuerdo de paz firmado, en unas capacidades reales de la sociedad amplia para la reconciliación y el disfrute de sus libertades de acción, deliberación y proyección en una sociedad sin conflicto armado. La dificultad en este punto es establecer cuál proyección de esa sociedad puede incluir a todos los afectados y no afectados por situaciones de injusticia. Es decir, el foco de atención se traslada a la pregunta por los quienes de la justicia a partir del posacuerdo de la Habana de cara a la reconciliación política, pero también, con la confluencia de conflictos sociales y de criminalidad exacerbados por el incremento de agrupaciones criminales ocupando los espacios liberados por la guerrilla de las FARC-EP.

El debate de las concepciones de justicia se concluye con el aporte de Benhabib, la cual propone la discusión entre el deber ser y los límites en lo procedimental de lo justo, buscando responder a qué justicia. La que construye ampliando la concepción política y normativa de esta sobre la base conceptual del universalismo interactivo, definido como: [...] una defensa posilustrada del universalismo, sin apuntalamientos metafísicos ni presuntuosidad histórica, [el cual] es aún viable. Tal universalismo sería interactivo, no legislativo, conocedor de las diferencias entre géneros, no ciego a ellas, sensible al contexto y no indiferente a las situaciones (Benhabib, 2006 [1992], p. 15).

Esta propuesta en una teoría moral "[...] permite reconocer la dignidad del otro generalizado a través del reconocimiento de la identidad moral del otro concreto" (Benhabib, 2006 [1992], p. 189). Sin embargo, no se trata de una discusión dicotómica entre lo uno u otro, sino de una mirada ampliada del universalismo, lo que Auat (2011) también ha llamado "universalismo situado". El planteamiento de Benhabib por su importancia para lo que interesa defender aquí se sintetiza en la siguiente tabla 1: 
Tabla 1. La perspectiva de justicia desde el universalismo interactivo en S. Benhabib

\begin{tabular}{|c|c|c|c|c|c|}
\hline $\begin{array}{l}\text { Comprensión } \\
\text { del otro }\end{array}$ & $\begin{array}{l}\text { Concepción } \\
\text { del individuo }\end{array}$ & $\begin{array}{l}\text { Normas de } \\
\text { relacionamiento }\end{array}$ & $\begin{array}{c}\text { Categorías } \\
\text { morales } \\
\text { imperantes }\end{array}$ & $\begin{array}{c}\text { Sentimientos } \\
\text { morales } \\
\text { con el otro }\end{array}$ & $\begin{array}{l}\text { Visión de la } \\
\text { comunidad }\end{array}$ \\
\hline $\begin{array}{l}\text { El otro } \\
\text { generalizado }\end{array}$ & $\begin{array}{l}\text { Ser racional, } \\
\text { habilitación } \\
\text { de mismos } \\
\text { derechos y } \\
\text { deberes de } \\
\text { nosotros. } \\
\text { Abstracción } \\
\text { de lo común. }\end{array}$ & $\begin{array}{l}\text { Normas de } \\
\text { reciprocidad } \\
\text { formal-públicas, } \\
\text { institucionales-, } \\
\text { se debe esperar } \\
\text { de nosotros lo } \\
\text { que esperamos } \\
\text { de los otros. }\end{array}$ & $\begin{array}{l}\text { Derecho, } \\
\text { obligaciones y } \\
\text { retribución. }\end{array}$ & $\begin{array}{l}\text { Respeto, } \\
\text { deber, mérito, } \\
\text { dignidad. }\end{array}$ & $\begin{array}{l}\text { Derechos y } \\
\text { habilitaciones. }\end{array}$ \\
\hline $\begin{array}{l}\text { El otro } \\
\text { concreto }\end{array}$ & $\begin{array}{l}\text { Ser racional } \\
\text { con historia } \\
\text { concreta, con } \\
\text { identidad y } \\
\text { constitución } \\
\text { afectivo- } \\
\text { emocional. } \\
\text { Importa su } \\
\text { distintividad. }\end{array}$ & $\begin{array}{l}\text { Normas de } \\
\text { reciprocidad } \\
\text { complementaria } \\
\text {-incluyentes, } \\
\text { aunque privadas-: } \\
\text { se espera del otro, } \\
\text { comportamientos } \\
\text { con los que se } \\
\text { sienta reconocido, } \\
\text { confirmado en } \\
\text { sus necesidades, } \\
\text { talentos y } \\
\text { capacidades }\end{array}$ & $\begin{array}{l}\text { Responsabilidad, } \\
\text { obligación y } \\
\text { distribución. }\end{array}$ & $\begin{array}{l}\text { Amor, } \\
\text { cuidado, } \\
\text { simpatía, } \\
\text { solidaridad. }\end{array}$ & $\begin{array}{l}\text { Necesidades } \\
\text { y solidaridad. }\end{array}$ \\
\hline
\end{tabular}

Fuente: elaboración propia, a partir de Benhabib (2006 [1992]) y Auat (2011, pp. 52-53).

La propuesta de Benhabib, procedimentalmente, se desarrolla a partir de la reciprocidad igualitaria, un principio cercano al argumento práctico de la paridad participativa de Fraser, planteando que "debemos tratarnos mutuamente como seres humanos concretos y fortalecer la capacidad de expresar este punto de vista creando, siempre que sea posible, prácticas sociales que materialicen el ideal discursivo" (Benhabib, 2006[1992], pp. 45-46).

El aporte de Benhabib en esta discusión, es que esos marcos valorativos de justicia no necesariamente se ubican en lugares epistémicos y normativos opuestos. Hablar de universalismo hoy requiere la discusión y aceptación de las singularidades y diversidades de población dentro de ese universalismo prevaleciente. Y, hablar de "otro concreto", en sus diferencias de capacidades y especificidades culturales, religiosas, políticas, sexuales, entre otras, requiere superar la mirada de particularismos aislados y esencialistas, hacia una comprensión de los contextos actuales interconectados y ampliados. Este reconocimiento 
es una condición cognitiva real para dar apertura a las posibilidades de lo paritario como un adjetivo fundamental en la noción de justicia actual.

Lo que a continuación propondré, es el análisis de acciones colectivas producidas en defensa de un tipo de justicia, cuya concreción nos ha permitido ensanchar ese horizonte de qué justicia ya no sólo en términos teóricos, sino también prácticos; en términos jurisprudenciales con la afirmación formal de derechos en la Constitución Política, pero también en términos cotidianos en el espacio de las opiniones de la gente y del sentido común.

\section{La imbricación entre vanguardias teóricas y las acciones afirmativas para la construcción de un nuevo marco valorativo de justicia}

Las demandas y percepciones de injusticia corresponden a unos marcos históricos, culturales, éticos y políticos; es decir, no son un asunto aislado. Pero ¿de qué dependen las variaciones o, en otro caso, las posibles formas estandarizadas de concebir, actuar y pensar socialmente la justicia? Cómo hemos discutido hasta aquí, esta es una preocupación que ha ocupado a estudiosos de distintas latitudes y disciplinas, en cada caso, llegando a enunciar el lugar condicionante, de constricción o legitimación que ocupa el entramado social o político para el establecimiento de criterios de definición de lo valorable o descartable, de lo indignante o no, de lo justo o injusto y, en general, de las expectativas de la buena vida individual y colectiva, lo que nos recuerda el planteamiento del clima cultural colectivo al que se refería Gramsci:

[...] cada acto histórico sólo puede ser cumplido por el "hombre colectivo". Esto supone el logro de una unidad "cultural-social”, por la cual una multiplicidad de voluntades disgregadas, con heterogeneidad de fines, se sueldan con vistas a un mismo fin, sobre la base de una misma y común concepción del mundo (general y particular, transitoriamente operante - por vía emocional- o permanente, cuya base intelectual está tan arraigada, asimilada y vivida, que puede convertirse en pasión). Si así son las cosas, revélese la importancia de la cuestión lingüística general, o sea, del logro de un mismo "clima" cultural colectivo. (Gramsci, 2017, pp. 24-25)

Uno de los asuntos centrales del debate sobre los marcos de justicia ha sido, si existe permanentemente la posibilidad de racionalizar/reflexionar acerca de cada decisión, teniendo en cuenta las valoraciones que enmarcan las actuaciones sociales y políticas, o si nos queda imposible suponer ese nivel de reflexividad por todos y en todos los instantes de la vida. ¿Están disponibles, cotidianamente la reflexión y el discernimiento para lo que va afectando a las personas en su día a día? ¿Existe libertad de 
acción y de enunciación de lo justo o injusto? Si no es así, ¿Qué es lo que opera en las distintas decisiones, pensamientos y formas de actuación acerca de lo justo o injusto?

Lo que producen los actores de las acciones afirmativas con sus distintas luchas a través de la historia, es mucho más que la demanda por el reconocimiento de una situación de discriminación y el trato no igualitario con respecto a la sociedad hegemónica. Lo que se logra, con la inclusión de derechos en las cartas constitucionales y con la creación de instancias garantes de su cumplimiento, tiene un significado más profundo que el significado práctico y político inmediato. Su significado es ontológico y axiológico, con la profundización de un deber ser ampliado al resto de la sociedad. En sintonía con esta idea Benhabib (2006 [1992]) nos ofrece con su planteamiento, la reflexión acerca del cambio de una política de "derechos y retribuciones" hacia una política de necesidades y solidaridad.

A lo largo de los debates teóricos de la justicia, lo que se va dejando de lado es la discusión por los significados políticos, sociales y normativos que prevalecen en la noción de justicia y sus variaciones. De este modo, las concepciones de la justicia desde las reivindicaciones prácticas de la movilización social, nunca han oscilado de manera lineal ni progresiva. Las demandas por la redistribución de la riqueza en el marco de una concepción del Estado de Bienestar, en la que prevaleció la noción de la igualdad en una perspectiva universalista para la inclusión socioeconómica; aparecieron desde comienzos del siglo XX en países que eran antiguas colonias europeas -británica para el caso de la India; ex colonias ibéricas, para el caso de los países de América Latina; o colonias francesas e italianas para el caso de países africanos, entre otras-y desde mediados de los años sesenta en Estados Unidos, las demandas sociales que buscaron ya no sólo manifestarse en demanda por la inclusión e igualdad económica, sino por el reconocimiento de identidades diversas en torno al género, la sexualidad, la etnia, las capacidades físicas y de estatus ciudadano. Es decir, la inclusión ya no sólo económica, sino también cultural, política y, de manera reciente, surgen esas reivindicaciones por la defensa de la dignidad moral de otras especies, entre estas, los seres no humanos.

Las expresiones de acciones afirmativas León y Holguín (2005) las diferencian dependiendo de la situación de discriminación normativa, esto es, por haber estado excluidos de los marcos normativos de los países desde sus constituciones nacionales o por su situación de vulnerabilidad social. Lo cual no necesariamente corresponde a aquellas personas que han sido discriminadas constitucionalmente, sino que han visto violados sus derechos, a causa de conflictos armados internos, como es el caso de la población desplazada en Colombia. Lo que nos hemos propuesto identificar es que estos sujetos históricamente discriminados, no sólo han sido víc- 
timas, sino que han sido quienes han permitido con sus acciones y reivindicaciones expresar una conciencia social de injusticia.

Esta conciencia social de injusticia acerca de la capacidad transformadora que tienen determinadas acciones afirmativas, ofrecen la posibilidad de enunciar problemas prácticos a los que nos enfrentamos teórica y axiológicamente al momento de adoptar una concepción particular, en la que individuos, diversas problemáticas sociales - pensando en el medio ambiente y los individuos no humanos como los animales-y grupos sociales histórica y sistemáticamente desatendidos y denostados, tendrían que dejar de ser excepciones en la aceptación de lo vivido como un trato justo y pasar a convertirse en la adopción generalizada de una concepción de justicia en la sociedad actual.

Las acciones afirmativas se han definido en la literatura especializada como una serie de medidas y atenciones que buscan corregir una historia de desigualdad sufrida por un grupo social o étnico, dentro de un estado nacional que lo discriminó negativamente desde sus procedimientos normativos legales y formales. Al intentar transformar esa situación se busca alterar los principios universalistas que dieron pie a tal discriminación (Carvalho, 2005).

Los avances de tipo afirmativo para la reducción de la desigualdad se han evaluado por los estudiosos del tema a partir de la existencia de una amplia jurisprudencia y las sentencias constitucionales específicas (León y Holguín, 2005), que comienzan a equiparar jurídicamente a grupos discriminados buscando lograr la igualdad real de oportunidades (Deere y León, 2002), a la par con la difusión y suscripción de convenios entre Estados nacionales y organismos multilaterales (Góngora, 2014), o con las reformas a las cartas magnas constitucionales - como es el caso de la Constitución Federal de Brasil en 1988 y la Constitución Política de Colombia en 1991-, reconociendo la diversidad étnica y cultural de ambos países (Sito y Kleiman, 2017) o, a través de la creación de políticas públicas focalizadas para un grupo poblacional o la creación de cuotas de participación política por parte de grupos minoritarios, históricamente discriminados (Oliven, 2007). Al mencionar sólo un ejemplo del mapa reciente de acciones afirmativas, nos encontramos con algunos de los mecanismos mencionados, detallados como sigue para el caso de Colombia (León y Holguín, 2005), ver tabla 2: 
Tabla 2. Acciones afirmativas por tipo de población y mecanismos creados en Colombia

\begin{tabular}{|l|l|}
\hline \multicolumn{1}{|c|}{ Población } & \multicolumn{1}{|c|}{ Medidas jurídicas } \\
\hline Mujeres & $\begin{array}{l}\text { Ley de cuotas en la política } \\
\text { Ley de la mujer rural } \\
\text { Mujeres cabezas de familia } \\
\text { Ley agraria 160 de 1994 } \\
\text { Edad menor de jubilación }\end{array}$ \\
\hline Adulto mayor & $\begin{array}{l}\text { Programa revivir } \\
\text { Filas especiales }\end{array}$ \\
\hline \multirow{3}{*}{$\begin{array}{l}\text { Población con alguna } \\
\text { limitación física }\end{array}$} & $\begin{array}{l}\text { Plan de atención a las personas con discapacidad } \\
\text { Observaciones estructurales para locomoción } \\
\text { Bibliotecas con sistema de lenguaje braille } \\
\text { Intérpretes en escuelas }\end{array}$ \\
\hline Minorías y grupos étnicos & $\begin{array}{l}\text { Participación en resguardos indígenas } \\
\text { Curules en la política } \\
\text { Sistema general de seguridad social en salud } \\
\text { Escuelas Bilingües e Interculturales } \\
\text { con docentes de la comunidad } \\
\text { Cátedra de Estudios Afrocolombianos } \\
\text { Titulación colectiva de tierras } \\
\text { Cupos en universidades }\end{array}$ \\
\hline Desplazamiento forzado & $\begin{array}{l}\text { Sistema nacional de atención integral } \\
\text { a la población desplazada }\end{array}$ \\
\hline \multirow{2}{*}{$\begin{array}{l}\text { Leyes de políticas } \\
\text { afirmativas en Colombia }\end{array}$} & $\begin{array}{l}\text { Constitución Política de 1991 } \\
\text { Ley 70 de 1993 } \\
\text { Convención 169 de la OrT } \\
\text { Plan de Acción Durban } \\
\text { Otros acuerdos nacionales e internacionales. }\end{array}$ \\
\hline
\end{tabular}

Fuente: con base en León y Holguín (2005).

Esta serie de medidas jurídicas buscan proteger y compensar a un grupo poblacional, de ahí su denominación de diferentes maneras, pero con el mismo propósito; entre estas, acciones positivas, acciones afirmativas, acciones de discriminación positiva o de discriminación inversa ${ }^{2}$, políticas afirmativas, entre otras, para entender la misma realidad.

2. Aunque el término "acciones de discriminación positiva" como lo ha sugerido el Relator Especial de Naciones Unidas sobre Acciones Afirmativas, tal denominación es una contradictio in terminis: "Affirmative action" is a term used frequently, but, unfortunately, not always with the same meaning. While in the minds of some the concept of "affirmative action" is also covered by the term "positive discrimination", it is of the utmost importance to stress that the latter term makes no sense. In accordance with the now general practice of using the term "discrimination" exclusively to designate "arbitrary", "unjust" or "illegitimate distinctions", the term "positive discrimination" is a contradictio in terminis: either the distinction in question is justified and legitimate, because not arbitrary, and cannot be called "discrimination", or the distinction in question is unjustified or illegitimate, because arbitrary, and should not be labelled "positive" (UN, 2002). Agradezco esta observación a un evaluador anónimo que amablemente brindó la citación. 
La voluntad de atender y compensar una situación discriminatoria procede de un actor con capacidad de decidir, agendar políticas y legislar - tribunales constitucionales, gobiernos del orden nacional y local-. En este enfoque de las acciones afirmativas orientadas desde el aparato estatal, de manera implícita se recoge el planteamiento rawlsiano de la justicia y su preocupación por el establecimiento de "instituciones justas" y de efectivo funcionamiento, dado que "la justicia es la primera virtud de las instituciones sociales" (Rawls, 1995 [1971], p. 17).

Para que las acciones positivas se produzcan, se consoliden y materialicen, de manera invariable, han requerido del posicionamiento de actores sociales y políticos, que a través de cientos de años y de sus construcciones identitarias han buscado el reconocimiento público, frente a las situaciones históricas de discriminación por razones de pertenencia a una "raza”, etnia, sexo, lengua o alguna limitación física, de las que habían sido objeto por parte de la sociedad hegemónica. Por tanto, cobra aquí toda la fuerza explicativa el planteamiento de los derechos como conquistas históricas, libradas mediante procesos sociales amplios, primero de conocimiento de una realidad diferencial a la preponderante y, segundo, del reconocimiento de las diferencias entre la población.

Esta perspectiva, que en Europa, Estados Unidos y América Latina se experimentó en el discurso jurisprudencial desde la segunda mitad del siglo XX: en defensa de la igualdad de las mujeres a partir de 1960, en defensa del principio de la igualdad racial en el caso de Estados Unidos a partir de 1965 o en defensa de poblaciones afro descendientes e indígenas a partir de la década de 1980, respectivamente, pero que tiene sus orígenes en acontecimientos históricos y políticos que nos remontan a la Ilustración y el triunfo de las ideas de igualdad, equidad y fraternidad de la Revolución francesa definidas en la promulgación de derechos, y posteriormente, en Estados Unidos, a partir de 1865, con la Décimotercera Enmienda constitucional que permitió la eliminación de la esclavitud. Además, habría que agregar a este breve barrido los distintos procesos de descolonización que buscaron eliminar privilegios fundados en la procedencia o el linaje, como fue el caso de la India frente a Gran Bretaña y, que se extendió también hasta mediados del siglo XX para las medidas formales.

Ahora bien, en la adopción de medidas materiales de justicia en términos de igualdad de condiciones, el resultado no es automático ni correspondiente a las acciones jurídicas de igualación. Es decir, estas son medidas institucionales que pueden facilitar las valoraciones disponibles de justicia, pero también depende de la capacidad individual para discernir, esperar y decidir con criterios de lo justo o no, con respecto a lo cual es necesario aceptar un lastre cultural como es el racismo, mucho más complejo para la eliminación de la discriminación y la exclusión. 
De este modo, el camino de los avances producidos con las acciones afirmativas en Colombia no ha sido en ningún caso lineal o progresista. En pleno siglo XXI se pueden mencionar dilemas infranqueables para la reducción de la desigualdad, algunos de ellos se retoman del planteamiento de León y Holguín (2005) estos son: la dinámica del mercado que va en contravía de la consecución de una igualdad de oportunidades debido a que con los procesos de privatización se dificulta el acceso a una educación gratuita; la naturalización de la desigualdad y el poco compromiso de la sociedad, en general, frente a la necesidad de la distribución económica y demás medidas para la superación de las desigualdades de todo tipo; la acumulación de desigualdades, ampliando los niveles de vulnerabilidad y exclusión de la participación, así como la ubicación en puestos públicos de decisión política de la población históricamente marginada; diversidad cultural versus igualdad, lo que obliga a pensar en la concepción de un otro generalizado versus un otro concreto desde la concepción defendida por Benhabib (2006 [1992]) que implica el conocimiento de las particularidades sociohistóricas y culturales de los denominados otros y por último la necesidad de ampliar la igualdad en el ámbito local y nacional al global, desde la perspectiva de un destino común.

Por la relevancia de algunos de estos aspectos mencionados, es precisamente, que el impacto y logro real no puede ser leído de forma unidimensional a partir de la producción legalista y formal de políticas afirmativas. Lo que hace perentoria la lectura vinculante entre la formulación de dichas políticas por parte de las distintas instancias que de manera efectiva las han producido normativamente en los contextos nacional e internacional, y los actores que por décadas se han estado movilizando y que buscan una demanda de atención igualitaria, a la par que el reconocimiento de sus diferencias. Invisibilizar el peso político que han tenido los actores organizados en defensa de sus derechos y en rechazo de la discriminación legal, cultural, política, económica y social de la que han sido objeto, contiene varios riesgos: uno de ellos es el de aparecer como políticas impositivas y retardatarias de las situaciones que requieren transformación; el otro riesgo es el de darle exclusivo peso protagónico y de voluntariedad a instancias públicas, negando acumulados sociales y culturales que son históricos y trascendentales.

El caso de la marcha de la población afroamericana exigiendo el derecho al voto, la no discriminación, así como la defensa de los derechos civiles y políticos en Selma (Alabama, Estados Unidos) en 1965, es un caso emblemático para estas políticas afirmativas. Esta, fue una de las primeras manifestaciones seguidas por televisión de forma masiva, y significó una ampliación de la solidaridad al resto de la población estadounidense ante la represión y violencia ejercida al conjunto de los manifestantes en esta marcha. El apoyo y solidaridad general del resto de la población estadounidense se presentó en los 
siguientes días de la marcha en Selma, al acompañar a los afroamericanos protagonistas de las manifestaciones a marchar de nuevo, esta vez desde Selma hasta llegar a Montgomory (Capital de Alabama), se obligó al presidente Lyndon Johnson, a que en marzo de 1965 promulgara la ley de derechos electorales, que prohíbe las prácticas electorales discriminatorias que priven del derecho al voto a los afro estadounidenses.

Este hecho, que se puede mencionar entre muchos otros, permite ampliar la discusión hacia un asunto defendido tangencialmente por los autores mencionados en la primera parte de este artículo, el asunto de que los cambios formales para la igualación jurídica por la condición racial, étnica, sexual, cultural, entre otros, requieren transformaciones más profundas en el ámbito ético y cultural, o mejor, en los patrones de valoración de lo justo y bueno, distanciando las posturas hegemónicas de racialización, construcción de estereotipos y estigmatización (Olaza, 2014), y exclusión de minorías (Soler y Pardo, 2008), en distintos ámbitos de la sociedad, entre los cuales el fundamental es la formación cultural y educativa en el reconocimiento de las diferencias (Mato, 2014; Sito y Kleiman, 2017).

Con respecto a los prejuicios y rasgos xenófobos, Olaza (2014) pregunta, ¿Qué porcentaje de acto consciente y racional existe? ¿Cuánto hay de historias de sedimentación de significantes, significados, sentidos conferidos, automatizados, naturalizados y actuados con sentimiento y emoción corporal? Lo que nos plantea un escollo fundamental en la igualación jurídica y en la eliminación de los procesos sistemáticos de exclusión y discriminación, debido a los discursos de racialización profundamente incorporados en la sociedad, hasta la actualidad. La noción de racialización nos propone asociar esa "raza" a valores morales y éticos - raza 'x' es buena gente, raza 'y' es gente mala-.

Salir del escollo moral que esto significa requiere la alteración de la mirada convencional o naturalizada de la discriminación, reflexionando acerca del significado de los discursos de quienes, a través de distintos medios, bien sean estos jurídicos, políticos, sociales, comunicacionales, se movilizan buscando un tratamiento igualitario, sin que esto implique la eliminación de las diferencias culturales.

\section{Conclusiones}

Los dos escenarios que han propiciado este debate acerca de qué justicia puede ofrecerle mayores garantías y proyección de una vida en bien-estar -como lo expresa Sen (2010)- , a una sociedad en transición del cierre de uno de sus conflictos armados y en emergencia de nuevas formas de conflictividad social y política como la colombiana, han sido el escenario de la reflexión a partir de autores que han venido pensando el 
tema y se convierten en las vanguardias intelectuales que nos permiten una comprensión y apertura de mira para la resolución. A su vez, el escenario de las acciones que han emprendido diversos colectivos y los Estados que se convierten en referentes prácticos en la búsqueda de un tratamiento equitativo en el reconocimiento de los derechos de grupos poblacionales que han sido histórica y sistemáticamente discriminados.

Se han focalizado distintos asuntos que resolver en esta adopción de qué justicia, lo que ha permitido constrastar aportaciones teóricas con situaciones prácticas que tendrán que ser dirimidas a partir de la adopción de un marco de justicia incluyente, basado en las capacidades, el reconocimiento del sufrimiento individual de las víctimas, pero también de la valoración universal de la sociedad desde una perspectiva interactiva, que tenga en cuenta los contextos locales y las singularidades personales en la garantía del trato justo por parte de la estructura social dominante.

Los distintos asuntos tienen su núcleo de resolución en dos principales, el primero es un asunto procedimental, frente al cual la estructura social imparcial propuesta por Rawls, permite asumir una vía de solución para una sociedad justa otorgándole toda la relevancia y centralidad a las instituciones sociales y políticas en la garantía de la igualación y cobertura universal de derechos, que tienen que prevalecer sobre cualquier interés particular que intente usurpar ese espacio -entre estos posibles usurpadores: el sector empresarial, los partidos políticos ó los grupos armados ilegales de cualquier índole-.

El segundo asunto no se enfoca en el proceso o procedimiento para llegar a esa sociedad justa sino en el resultado, poniendo el énfásis en quienes son los grupos susceptibles a un tratamiento igualitario, desde la comprensión de las capacidades de gestión y de funcionamiento de las personas en la perspectiva de Sen, o de lo que efectivamente pueden llegar a hacer y ser en la perspectiva Nussbaumniana. Frente a los cuales la sociedad colombiana tendrá que buscar inclusión en el tipo de justicia a construir, dado que estamos en mora aún del reconocimiento de derechos y capacidades de diversos grupos poblacionales, a los que es imprescindible agregar las distintas víctimas de conflictos armados en proceso de inicio de una vida en civilidad.

Lo que se propone con la apertura de este debate es que la forma como se ha ensanchado la justicia con estos dos escenarios, nos permite contar con un acervo de aspectos imprescindibles hoy para la noción de justicia, que tendríamos que poner en práctica en el recorrido de esa reconciliación a partir de unos acuerdos de paz firmados en la Habana. Asumir este debate nos puede permitir la comprensión de los diferentes riesgos y retos a los que estamos abocados; entre estos, el camino del revanchismo y la venganza contra los perpetradores de la pasada violencia; el del silencio y el ocultamiento de los hechos vividos durante el conflicto, con el consecuente desconocimiento 
de la verdad, la ausencia de una memoria de lo ocurrido y de la desresponsabilización de la violencia perpetrada, lo que podría encerrar nuevos ciclos de violencia. Las líneas limítrofes de esos caminos por recorrer en la adopción y configuración de una justicia para la reconciliación social son muy tenues y débiles, de ahí la gran envergadura de esta tarea que a todos nos compete.

\section{Referencias}

Auat, A. (2011). Hacia una filosofía política situada. Buenos Aires: Waldhuter Editores.

Benhabib, S. (2006 [1992]). El ser y el otro en la ética contemporánea. Feminismo, comunitarismo y posmodernismo. Barcelona: Gedisa Editorial.

Carvalho, J. J. (2005). Inclusão Étnica e Racial no Brasil. São Paulo: Attar Editorial.

Deere, C. D. y León, M. (2002). Género, propiedad y empoderamiento: tierra, Estado y mercado en América Latina. Bogotá: Tercer Mundo Editores - Facultad de Ciencias Humanas Universidad Nacional.

Fraser, N. (2008). Escalas de justicia. Barcelona: Editorial Herder.

Fraser, N. y Honneth, A. (2006). ¿Redistribución o reconocimiento? Madrid: Ediciones Morat.

Góngora, M. E. (2014). Geopolíticas de la identidad: la difusión de acciones afirmativas en los Andes. Universitas Humanística, 77, 35-69.

Gramsci, A. (2017). Materialismo histórico, filosofía y política moderna. Granada: Editorial Comares.

Honneth, A. (2010). Reconocimiento y menosprecio. Sobre la fundamentación normativa de una teoría social. Madrid: Katz Editores - Centro de Cultura Contemporánea de Barcelona. Honneth, A. (2011). La sociedad del desprecio. Madrid: Editorial Trotta.

León, M. y Holguín, J. (2005). Acción afirmativa: hacia democracias inclusivas. Santiago de Chile: Fundación Equitas.

Matta Colorado, N. R. El desafío que traen las bandas para 2018. (15 de enero de 2018). El Colombiano. Recuperado de http://www.elcolombiano.com/colombia/el-desafioque-traen-las-bandas-para-2018-YG8008054

Mato, D. (2014). Universidades indígenas en América Latina. Experiencias, logros, problemas, conflictos y desafíos. ISEES. Inclusión Social y Equidad en la Educación Superior, 14, 17-45. Recuperado de https://dialnet.unirioja.es/ejemplar/379833

Nussbaum, M. C. (2016 [2006]). Las fronteras de la justicia. Consideraciones sobre la exclusión. Bogotá: Editorial Planeta.

Olaza, M. (2014). Políticas públicas y cultura política. Reflexiones posibles para des-naturalizar prejuicios, estereotipos y racismo. En A. Grimson (Comp.), Culturas políticas y políticas culturales (pp. 133-144). Buenos Aires: Fundación Altos Estudios Sociales - Clacso. 
Oliven, A. C. (2007). Ações afirmativas, relações raciais e política de cotas nas universidades: uma comparação entre os Estados Unidos e o Brasil. Educação, 30(1), 29-51. Rancière, J. (2010 [2003]). El maestro ignorante. Barcelona: Laertes editorial.

Rawls, J. (1995 [1971]). Teoría de la justicia. México: Fondo de Cultura Económica.

Sen, A. (1995). Nuevo examen de la desigualdad. Madrid: Alianza Editorial.

Sen, A. (2010). La idea de la justicia. México: Taurus.

Sito, L. y Kleiman, A. B. (2017). "Eso no es lo mío": un análisis de conflictos en la apropiación de prácticas de literacidad académica. Universitas Humanística, 83, 153-179. https://doi.org/10.11144/Javeriana.uh83.acap

Soler, S. y Pardo, N. (2008). Colômbia: invisibilidade e exclusão. En T. Van Dijk (Coord.), Racismo e discurso na América Latina (pp. 159-201). São Paulo: Editora Contexto.

United Nations (UN). (2002). Prevention of Discrimination. The Concept and Practice of Affirmative Action Final Report Submitted by Mr. Marc Bossuyt, Special Rapporteur, in Accordance with Sub-Commission Resolution 1998/5. Sub-Commission on the Promotion and Protection of Human Rights. Recuperado de https://digitallibrary.un.org/record/467997/files/E_ CN.4_Sub.2_2002_21-EN.pdf

\section{Cómo citar}

Alzate Zuluaga, M. L. (2018). Valoraciones de la justicia y las acciones afirmativas. Reflexiones a partir de la firma de los acuerdos de paz de Colombia en 2016. FORUM. Revista Departamento Ciencia Política, 14, 91-112. 